\title{
A LITERATURE REVIEW
}

\section{for}

\section{The California Bone Health Campaign For Low-Income Latino Mothers}

California Project LEAN

California Department of Health Services

Public Health Institute

Funded by:

California Nutrition Network

through the United States

Department of Agriculture

Prepared by:

Sarah Coffey, B.S.

Cyndi Guerra-Walter, B.A.

Elizabeth Bell, M.S., R.D., C.D.E.

Peggy Agron, M.A., R.D.

Special acknowledgement to:

Noralee Cole

Jennifer Bernardo, B.S.

\section{April 2000}




\section{Table of Contents}

EXECUTIVE SUMMARY---1

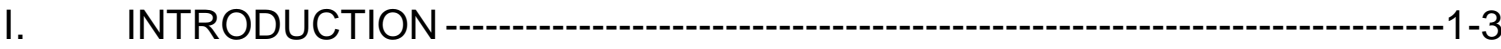

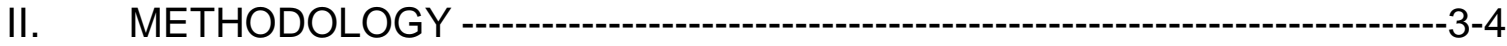

III. FINDINGS -- 4

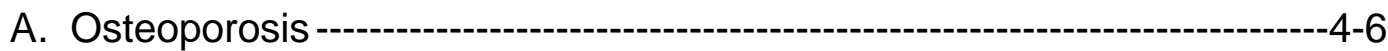

1. Prevalence-----------o- 4

2. Osteoporotic Fracture -------------- 5

3. Achieving and Maintaining Bone Mass ---------------- 6

4. Risk Factors Associated with Bone Health ---------------------- 6

B. Dietary Factors ---ons

1. Recommended Calcium Intake -----------------------------6-7

2. Actual Calcium Intake ---

3. Sources of Calcium ---

4. Barriers to Consuming Adequate Calcium-------------------11-12

5. Knowledge, Perceptions, and Attitudes about Calcium and Dairy Foods--------------------------------- 13-14

6. Food Purchasing, Food Preparation, and Meal Patterns ------------14

C. Physical Activity--

1. Recommended Levels--

2. Actual Levels ---ove-15

3. Physical Activity Preferences-----------------------------16

4. Barriers to Physical Activity ------o-16

5. Knowledge, Perceptions, and Motivators

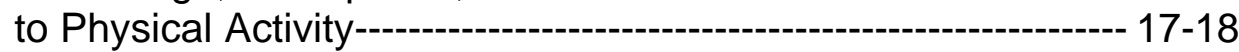

D. Overview of Dairy and Physical Activity Campaigns------------------------18

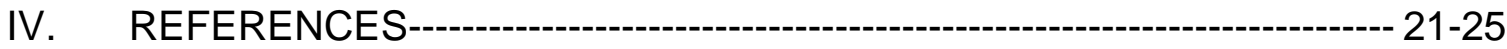




\section{EXECUTIVE SUMMARY}

A literature review was conducted by California Project LEAN (Leaders Encouraging Activity and Nutrition), a program of the California Department of Health Services and Public Health Institute, on behalf of the California Bone Health Campaign for Low-Income Latino Mothers. California Project LEAN was awarded a grant by the United States Department of Agriculture-funded California Nutrition Network for Healthy, Active Families (California Nutrition Network) to conduct formative research for an osteoporosis primary prevention campaign targeting pre-menopausal foodstamp eligible women in California.

The purpose of the literature review was to identify the following information for foodstamp eligible women-primarily African American, Caucasian, and Latino mothers: (1) prevalence and risk factors of osteoporosis; (2) dietary factors, physical activity behaviors, as well as food preparation and shopping habits; (3) barriers and motivators to dietary and physical activity behaviors that promote bone health; (4) knowledge, attitudes, and perceptions of osteoporosis in addition to dietary and physical activity behaviors that promote bone health; (5) appropriate channels and strategies that may result in a positive behavior change; (6) lessons learned from available research on intervention strategies; and, (7) recommendations for intervention approaches. This literature review will contribute to the development of a social marketing plan by guiding efforts to narrow the target audience, identify the target behavior and behavioral objective.

Approximately 45 articles, studies and reports on the key topics surrounding bone health were reviewed. With a few exceptions, the research articles reviewed were comprised of or included females 20 to 40 years of age from many racial/ethnic groups, and were published in or after 1995 in academic and popular journals with subjects limited to osteoporosis, bone health, calcium, milk/dairy consumption, and physical activity or exercise. Unpublished qualitative research reports from focus groups conducted by the National Osteoporosis Foundation, California Nutrition Network and California Project LEAN were also reviewed.

\section{Important Findings}

The research showed that although non-Hispanic white women are disproportionately afflicted with osteoporosis, Hispanics and African Americans suffer from osteoporosis in significant numbers. According to the most current prevalence figures, California has the greatest number of women with osteoporosis of any state. In 1996, there was an estimated 2.7 million women age 50 and over in California who had osteoporosis or were at risk for developing the disease due to low bone mass. In 2015, this number is expected to increase to 4.9 million.

The literature review revealed that the promotion of bone health is a multi-faceted, lifelong undertaking with two main objectives: (1) to increase peak bone mass in early life, and (2) to minimize bone loss later in life. Increasing calcium and 
vitamin D intakes and physical activity, particularly weight-bearing physical activity, have shown positive effects on bone gain and prevention of bone loss in clinical studies.

Although eating a balanced diet rich in calcium is one of the most important bone health strategies, the average American woman's calcium intake falls well below the Dietary Reference Intakes (DRIs) in all age groups and among all race/ethnic groups. Most studies revealed that mean daily intake of calcium is highest for Hispanic and non-Hispanic white females and lowest among black females, but lower than the recommended level for all racial/ethnic groups.

The largest source of dietary calcium among most ethnic/racial groups is milk and dairy products; however, other sources of calcium are important for achieving the recommended calcium intakes of 1,000 to 1,200 milligrams per day. Barriers to consuming adequate calcium-rich foods and beverages include lactose intolerance, taste, and competing foods such as soda. Availability is a barrier to low-fat milk consumption.

The research also revealed that consistent physical activity is one of the most effective bone health promotion strategies. One study suggested that sedentary people begin losing bone in their 20s. Over half of adults and almost half of young people aged 12-21 do not participate in vigorous physical activity. Among women who do exercise, walking is the most commonly reported activity. The perceived benefits of being physically active are numerous and include relieving stress, increasing vitality and health, promoting sleep, promoting weight loss, allowing women to set a good example for their children, helping children release energy as well as develop socially and emotionally, and bettering the community (e.g., walking clubs as crime prevention).

\section{Gaps in the Literature}

The literature offered a wealth of information on topics surrounding bone health for the target audience; however, the literature review was not able to identify many reports and publications available on bone health intervention programs targeting multi-ethnic, low-income, pre-menopausal women and their families. Most awareness and intervention efforts have focused on post-menopausal women and addressed issues of hormone replacement therapy, fall prevention in the elderly, screening, diagnosis, and treatment, or lifestyle factors such as smoking cessation and decreased alcohol consumption. Some states, such as Washington, have recently implemented bone health campaigns targeting pre-menopausal or lowincome women; however, reports and publications addressing the challenges, successes, failures and strategies have not yet been published. 


\section{Introduction}

\section{Background}

Osteoporosis, the most prevalent metabolic bone disease in the United States, is a major public health challenge (National Institutes of Health, 2000). The need for education and prevention interventions among women of all ages is receiving greater emphasis than ever before.

Osteoporosis affects more than 28 million Americans and costs the country over $\$ 13$ billion per year. In California, approximately 3.4 million men and women have osteoporosis or low bone mass. The cost of treating osteoporosis in California is estimated at $\$ 2$ billion per year. Without the implementation of intervention efforts, by the year 2015, 5.7 million men and women will have osteoporosis or low bone mass and the financial burden may increase to $\$ 24$ billion per year (National Osteoporosis Foundation, 1997).

Primary prevention of osteoporosis involves taking behavioral steps that maximize and maintain bone mass. Preventative steps that foster bone health, as well as many other health benefits, include consuming a healthy diet rich in calcium and vitamin $D$ and engaging in regular physical activity (Heaney, 1996).

\section{Campaign Goals and Target Audience}

In October of 1999, California Project LEAN (Leaders Encouraging Activity and Nutrition), a program of the California Department of Health Services (DHS) and the Public Health Institute, was awarded one-year funding by the California Nutrition Network for Healthy, Active Families (Network). This funding will support formative research to plan and develop an osteoporosis primary prevention, social marketing campaign, The California Bone Health Campaign for Low-Income Latino Mothers. The United States Department of Agriculture (USDA), which funds the Network, requires that the projects it funds target the largest groups using food assistance programs. In accordance, the initial primary target audience of The California Bone Health Campaign for Low-Income Latino Mothers will include the segments of the following food stamp participants in California with an average annual income of less than $\$ 20,000$ : single, separated, or divorced white or African American women with children of lower elementary age, and married Latino* mothers with children of upper elementary age. The secondary target audience will include the family members of the primary target audience, particularly their children.

\footnotetext{
* It is important to note that the following findings include information on Latino, Hispanic, and Mexican American women. The racial/ethnic classifications reported in this document are consistent with the classifications made in the original sources of information. One may not be able to generalize the information as Latinos, Hispanics, and Mexican Americans are heterogeneous populations.
} 
The California Bone Health Campaign for Low-Income Latino Mothers will target women and mothers - as the primary food shoppers, health advocates, and role models for their families - to increase the prevalence of dietary and physical activity behaviors that promote bone health among low-income, pre-menopausal women and their families in California. By targeting African American, Caucasian, and Latino mothers, The California Bone Health Campaign for Low-Income Latino Mothers will complement other efforts, such as the National Bone Health Campaign, which targets preadolescent and adolescent females. The National Bone Health Campaign is currently under development by the Centers for Disease Control and Prevention (CDC), the Department of Health and Human Services Office on Women's Health, and the National Osteoporosis Foundation. (United States Public Health Services Office on Women's Health, United States Department of Health and Human Services, and the National Osteoporosis Foundation, 1996)

\section{Campaign Objectives}

The 1999-2000 objectives for The California Bone Health Campaign for Low-Income Latino Mothers will focus on research and planning. Formative research for the Campaign involved key informant telephone interviews with physicians, researchers, nutritionists, public health officials, marketing experts, and officials of non-profit organizations familiar with bone health issues and interventions; an environmental scan of bone health efforts currently underway throughout the United States; and this literature review. The health policy, program, and research firm of Samuels \& Associates was hired to conduct the key informant interviews and the environmental scan.

An analysis of the key informant surveys, environmental scan, and literature review, in addition to an analysis of commercial market research and original focus groups, will be used to develop the social marketing communication plan by the end of the first year. The social marketing communication plan will establish the foundation of the campaign. The literature review will contribute to the development of the communication plan by guiding efforts to narrow the target audience as well as identify the target behavior and communication objective.

The main objectives of the literature review were to identify the following information for the primary target audience of low-income, pre-menopausal African American, Caucasian, and Latino mothers:

1) Prevalence and risk factors of osteoporosis;

2) Dietary factors, physical activity behaviors, in addition to food preparation and shopping habits;

3) Barriers and motivators to dietary and physical activity behaviors that promote bone health; 
4) Knowledge, attitudes, and perceptions of osteoporosis in addition to dietary and physical activity behaviors that promote bone health;

5) Appropriate channels and strategies that may result in positive behavior changes;

6) Lessons learned from available research on intervention strategies; and,

7) Recommendations for intervention approaches.

\section{Methodology}

The following literature review is a summary of approximately 45 articles, studies, and reports on the key topics surrounding bone health. The articles were identified through a literature search and referrals from California Project LEAN staff, key informants, and partners.

The Public Health Library of the University of California, Berkeley, conducted a focused literature search, exploring hundreds of computerized databases. Provided with a list of key words and an outline, the Public Health Library created a bibliography of current articles relating to osteoporosis, bone health, and the physical activity and dietary behaviors of pre-menopausal women, particularly low-income African American, Caucasian, and Latino mothers, when available.

With a few exceptions, research articles were selected based on the following criteria:

- Study sample was comprised of or included females 20 to 40 years of age from many racial/ethnic groups;

- Study was published in or after 1995 in academic and popular journals; and,

- The main subject of the article was osteoporosis, bone health, calcium, milk/dairy consumption, and physical activity or exercise.

The following unpublished qualitative research reports were also reviewed.

\section{National Osteoporosis Foundation}

In 1997, Fleishman-Hillard Research, Inc., conducted focus and discussion groups to guide the development of the National Bone Health Campaign targeting pre-adolescent and adolescent girls. The discussion groups included 17 mothers of girls ages 9 to 12 in Chicago, Illinois, and San Francisco, California. Eight of the participating mothers were Caucasian, four were Asian American, three were African American, and two were Hispanic. 


\section{California Nutrition Network for Healthy, Active Families}

\section{Focus Group Research with Low-Income White, African American, and Latino Women with School-Aged Children Who Do and Do Not Use Food Stamps}

In the summer of 1997, 20 focus groups were conducted by the Network in Fresno, San Jose, and Los Angeles, California in order to develop a healthy eating and physical activity social marketing campaign targeting low-income women in California. The participants were 19 to 45 years of age, mothers with children between the ages of 5 and 18, and had an annual income of less than $\$ 20,000$. The groups were mixed with regards to ethnicity. White, African American, Spanish-dominant Latinas, and Englishdominant Latinas were included. The women were asked about their typical eating, shopping and physical activity behaviors.

\section{California Project LEAN Research}

\section{Eating Habits of Latinos: Topline Report}

In June of 1995, approximately 40 Spanish-dominant Latinas took part in four focus groups in San Jose and Los Angeles, California. Juarez and Associates conducted the focus groups regarding low fat foods.

\section{Findings}

The literature offered a wealth of information on topics surrounding bone health for the target audience. The literature review was not able to identify many reports and publications available on bone health programs targeting pre-menopausal women. Most awareness and intervention efforts have focused on post-menopausal women and addressed issues of hormone replacement therapy; fall prevention in the elderly; screening, diagnosis, and treatment; or lifestyle factors such as smoking cessation and decreased alcohol consumption. Some states, such as Washington, have recently implemented bone health campaigns targeting pre-menopausal or low-income women; however, reports and publications addressing the challenges, successes, failures, and strategies have not yet been published.

\section{A. Osteoporosis}

\section{Prevalence and Fiscal Impact}

Osteoporosis, the most prevalent metabolic bone disease in the United States, is a major public health challenge (National Institutes of Health, 1994). The need for education and prevention interventions among women of all ages is receiving greater emphasis than ever before.

Osteoporosis affects more than 28 million Americans, 80 percent of whom are women. In California, approximately 3.4 million men and women have osteoporosis or low bone mass. On average, every American woman has a one-in-two chance of suffering an 
osteoporosis-related hip, spine, or wrist fracture. Twenty percent of those with an osteoporosis-related hip fracture die within a year of their injury (National Osteoporosis Foundation, 2000). Although non-Hispanic white women are disproportionately afflicted with the disease, Hispanics and African Americans suffer from osteoporosis in significant numbers (Table 1) (Looker, et al., 1995).

\begin{tabular}{|l|c|}
\hline \multicolumn{2}{|c|}{$\begin{array}{c}\text { Table 1: Prevalence of Osteoporosis in Women } \\
\text { 50 Years and Older By Ethnicity }\end{array}$} \\
\hline Non-Hispanic white & $21 \%$ \\
\hline Mexican American & $16 \%$ \\
\hline Non-Hispanic black & $10 \%$ \\
\hline $\begin{array}{l}\text { Data from the Third National Health and Nutrition Examination } \\
\text { Survey (NHANES III) (Looker, et al., 1995) }\end{array}$ \\
\hline
\end{tabular}

Prepared by the California Department of Health Services

African American women are at significant risk for developing osteoporosis even though they tend to have higher bone mineral density than Caucasian women. As African American women age, their risk tends to be similar to the risk among Caucasian women. In addition, African American women are more likely to die following a hip fracture than Caucasian women (National Institutes of Health, Osteoporosis and Related Bone Disorders, National Resource Center, 2000).

Latino women are also at a significant risk for developing osteoporosis. The large Latino population of California, which is growing at a faster rate than non-Latino, is a contributing factor to the burden of osteoporosis within the state (National Institutes of Health, Osteoporosis, and Related Bone Disorders, National Resource Center, 2000). According to the most current prevalence figures, California has the greatest number of women with osteoporosis of any state. In 1996, there was an estimated 2.7 million women age 50 and over in California who had osteoporosis or were at risk for developing the disease due to low bone mass. In 2015, this number is expected to increase to 4.9 million (National Osteoporosis Foundation, 1997).

Osteoporosis costs the country over $\$ 13$ billion per year. The cost of treating osteoporosis in California is estimated at $\$ 2$ billion per year. Without the implementation of intervention efforts, by the year 2015, 5.7 million men and women will have osteoporosis or low bone mass and the financial burden may increase to $\$ 24$ billion per year (National Osteoporosis Foundation, 1997).

\section{Osteoporotic Fracture}

Hip, spine, and wrist fractures and their complications are the most common medical consequences of osteoporosis. Following a fracture, 66 percent of hip fracture patients are unable to return to their previously independent lifestyle and ten to 20 percent die within one year. A woman's risk of a hip fracture due to osteoporosis is equal to her 
combined risk of uterine, ovarian, and breast cancer (Women's Health Council of the Association of State and Territorial Chronic Disease Program Directors, 1999).

\section{Achieving and Maintaining Bone Mass}

The promotion of bone health is a multi-faceted, lifelong undertaking with two main objectives: to increase peak bone mass in early life, and to minimize bone loss later in life (Leslie \& Pierre, 1999; Heaney, 1996).

Peak bone mass usually occurs at an average age of 18 in American females, after linear growth has ceased. However, one study reported that bone gains may occur until the age of 35 (Rodin et al., 1990). A longitudinal, prospective study of up to five years found that a gain in bone mass did occur in 20 to 29 year-old women with mean calcium intakes of 786 milligrams and physical activity levels that were not extremely high. The study, which did not conduct any intervention, concluded that increases in total bone mass of up to 12.5 percent may occur in white females in their 20's. This bone gain could be achieved with relatively modest increases in physical activity and calcium intake and should not be ignored (Recker et al., 1992).

Once peak bone mass is achieved there is a plateau period of approximately 10 to 15 years in which constant turnover of bone occurs but the mass remains fairly constant. Bone loss usually begins around the age of 40 . Bone loss in women increases after menopause. The higher the peak bone mass, the longer it will take for bone losses to increase the risk of fracture (Leslie \& Pierre, 1999).

\section{Risk Factors Associated with Bone Health}

There are many factors involved in building and maintaining skeletal health throughout life. Genetics, lifestyle, nutrition, medical conditions, and certain medications can influence peak bone mass. Controllable risk factors, those amenable to intervention, include nutrition and lifestyle factors such as calcium and vitamin D intakes and physical activity (Leslie \& Pierre, 1999). Increasing calcium and vitamin D intakes and physical activity, particularly weight-bearing physical activity, have shown positive effects on bone gain and prevention of bone loss in clinical studies (Recker et al., 1992). The positive effects of adequate calcium intake and physical activity earlier in life may be considerable in terms of fracture prevention later in life.

\section{B. Dietary Factors}

\section{Recommended Calcium Intake}

The revised nutrient and energy standards known as Dietary Reference Intakes (DRIs) have replaced the Recommended Dietary Allowances (RDAs)(Table 2). The National Academy of Sciences revised the recommendations based on the calcium requirements necessary for optimal bone deposition earlier in life, bone maintenance in middle age, and minimal bone loss later in life (National Academy of Sciences, 1997). 
Table 2: 1997 Dietary Reference Intakes (DRIs) for calcium by age

\begin{tabular}{|c|l|}
\hline Children & $500 \mathrm{mg}$ \\
\hline $1-3$ & $800 \mathrm{mg}$ \\
\hline $4-8$ & $1300 \mathrm{mg}$ \\
\hline Females & $1300 \mathrm{mg}$ \\
\hline $9-13$ & $1000 \mathrm{mg}$ \\
\hline $14-18$ & $1000 \mathrm{mg}$ \\
\hline $19-30$ & $1200 \mathrm{mg}$ \\
\hline $31-50$ & $1200 \mathrm{mg}$ \\
\hline $51-70$ & \\
\hline $71+$ & $\begin{array}{l}\text { Reference: Dietary Reference Intakes for Calcium, Phosphorus, Magnesium, Vitamin D, and } \\
\text { Fluoride (1997). }\end{array}$ \\
\hline
\end{tabular}

Prepared by Department of Health Services

The California Dairy Council has translated the new DRIs into four servings of highcalcium foods per day for females nine to 18 or over 51 years of age and three servings for females 19 to 50 (Dairy Council of California, 2000). At least one high-calcium food should be consumed with every meal (Weaver, 1997). High calcium food servings include one cup of milk, yogurt, calcium-fortified orange juice, pudding, and custard, or 1 $1 / 2$ ounces of cheese. Three servings of medium-calcium foods equal one high-calcium food serving. Medium calcium food servings include 1/2 cup of cottage cheese, frozen yogurt, and ice cream, one cup of beans, $1 / 4$ cup of almonds, one cup of broccoli or bok choy, and two corn tortillas (Dairy Council of California, 2000).

\section{Actual Calcium Intake}

Dietary calcium intake may be a predictor of overall dietary adequacy. Diets low in calcium are often low in many other essential nutrients, including vitamin D, vitamin B6 and magnesium (Miller, Groziak, \& DiRienzo, 1996). Despite the increasing number of research studies and health messages in the popular press stating the decreased risk of chronic disease associated with calcium, nutritional surveys reveal that calcium consumption among American women has not significantly improved over the last 20 years (Miller, Steinbach, \& Jarvis, 1995).

Although eating a balanced diet rich in calcium is one of the most important bone health strategies, the average American woman's calcium intake falls well below the DRIs in all age groups and among all race/ethnic groups (Table 3). In addition to the Third National Health and Nutrition Examination Surveys (NHANES III), most studies reveal that mean daily intake of calcium is highest for Hispanic and non-Hispanic white females and lowest among black females, but lower than the recommended level for all racial/ethnic groups (Alaimo et al., 1994). A study examining the dietary intake of Mexican American women found that second-generation Mexican American women had lower dietary intake of calcium than first-generation Mexican American women (Guendelman \& Adams, 1995). 


\begin{tabular}{|l|c|c|c|}
\hline \multicolumn{4}{|c|}{ Table 3: $\begin{array}{c}\text { Mean calcium intake in milligrams among females } \\
\text { by age and race-ethnicity }\end{array}$} \\
\hline \multicolumn{1}{|c|}{ Age } & $\begin{array}{c}\text { Non-Hispanic } \\
\text { White }\end{array}$ & $\begin{array}{c}\text { Non-Hispanic } \\
\text { Black }\end{array}$ & Mexican American \\
\hline All ages & 764 & 626 & 799 \\
\hline $1-2$ years & 843 & 699 & 832 \\
\hline $3-5$ years & 827 & 727 & 829 \\
\hline $6-11$ years & 879 & 755 & 958 \\
\hline $12-15$ years & 801 & 737 & 872 \\
\hline $16-19$ years & 866 & 725 & 816 \\
\hline $20-29$ years & 806 & 656 & 754 \\
\hline $30-39$ years & 788 & 574 & 847 \\
\hline $40-49$ years & 717 & 530 & 701 \\
\hline $50-59$ years & 660 & 564 & 701 \\
\hline $60-69$ years & 743 & 477 & 606 \\
\hline $70-79$ years & 651 & 549 & 593 \\
\hline 80 years and over & 633 & 484 & 595 \\
\hline $\begin{array}{l}\text { Data from the Third National Health and Nutrition Examination Survey, 1988-1991. (Alaimo, } \\
1994)\end{array}$ & \multicolumn{3}{|c}{} \\
\hline
\end{tabular}

Prepared by Department of Health Services

The USDA Continuing Food Survey of Food Intakes by Individuals (CFSII) conducted in 1994 to 1996, reported that 15 percent of women ages 20 to 29, 14 percent of women ages 30 to 39, and 11.5 percent of women ages 40 to 49 consumed the recommended 1000 milligrams of calcium per day (National Academy of Sciences, 1997).

\section{Sources of Calcium}

The largest source of dietary calcium among most ethnic/racial groups is milk and dairy products; however, other sources of calcium are important for achieving the recommended calcium intakes of 1,200 to 1,500 milligrams per day (American Academy of Pediatrics, 1999).

Many foods contain calcium, but the amount of calcium and the bioavailability, or absorption rate, of the calcium vary. One cup of California milk contains 276-348 milligrams of calcium, depending on the fat content. Some plant foods such as spinach, sweet potatoes, and beans contain fiber and compounds such as oxalates and phytates, which reduce the availability of the calcium they contain. For example, it would take 7.75 cups of cooked spinach to yield the same amount of bioavailable calcium in one cup of milk (Weaver, 1994).

\section{Dairy Sources}

An analysis of the nutrient content of the national food supply in 1994, suggests that dairy foods made a significantly nutrient dense contribution to the American diet. 
Though calories from dairy foods made up 9.3 percent of total calories, they provided approximately 73 percent of the calcium, 33 percent of the phosphorous, 30 percent of the riboflavin, 21 percent of the vitamin B12, 19 percent of the zinc, and 17 percent of the vitamin A in the American diet (Gerrior \& Bernie, 1997).

A study of the nutrient content of the American food supply from 1990 to 1994 conducted by the USDA indicated that 73 percent of calcium in the food supply was contributed by milk and milk products (National Academy of Sciences, 1997).

The Hispanic Health and Nutrition Examination Survey (HHANES) indicated that milk (whole and reduced fat) and cheese contributed 51 percent of total dietary calcium for Hispanic women (Block, Norris, Mandel \& DiSogra, 1995). Among Mexican Americans, customary foods that contain milk may include atole, a gruel eaten during the evening meal, and licuados, fresh fruit drinks consumed by adults and children. Milk may also be heated and flavored with sugar, chocolate, or cinnamon (Milk Industry Foundation, 1995). Milk flavored with coffee, known as café con leche, is widely consumed among Mexican Americans.

\section{Non-dairy Sources}

A study of the nutrient content of the American food supply from 1990 to 1994 conducted by the USDA indicated that nine percent of calcium in the American food supply was contributed by fruits and vegetables, five percent was contributed by grains and 12 percent came from other sources. Nationwide Food Consumption Surveys in 1987 and 1988 reported that fruits, vegetables, and grains contributed a greater proportion of dietary calcium for adults than for children. Fruits and vegetables provide other nutrients required for bone health, such as zinc, potassium, magnesium, betacarotene, and vitamin C. HHANES also reported that corn and flour tortillas contributed more than 10 percent and beans contributed three percent of total calcium in the diets of Hispanic women (Block, Norris, Mandel, \& DiSogra, 1995).

It is difficult for most Americans to achieve optimal calcium intake exclusively from vegetables, fruit, and cereal grains. Calcium-fortified foods and/or supplements may be instrumental in providing adequate calcium for individuals who choose not to eat dairy products (Weaver, 1997).

\section{Calcium Supplementation}

In the 1992 National Health Interview Survey, 5.6 percent of white participants reported using calcium supplements, compared to 2.1 percent of African American participants (Ford, 1998).

Increased dietary calcium from foods may be more beneficial than supplements. Good food sources of calcium also contribute magnesium, phosphorus, thiamine, riboflavin, and vitamins $C$ and D to the diet (Miller, Steinbach, \& Jarvis, 1995). 


\section{Milk and Dairy Purchasing and Consumption}

A report of the food consumption, prices, and expenditures for Americans from 1970 to 1997 (USDA, 1999) reported increases in consumption of cheese, yogurt, and lower fat milks and attributed these increases to the following:

- Generic advertising campaigns, such as the "Milk Mustache" Campaign, that improve the image of milk, especially lower fat versions;

- The adoption of lower fat milks by fast food restaurants and coffee chains, such as McDonald's and Starbucks;

- Introduction of new products, such as lower fat cheeses and shredded cheeses (including Italian and Mexican blends) in resealable bags;

- Increased consumption of convenience and prepared foods that feature cheese, such as pizza, tacos, fast-food sandwiches, and sauces.

In the United States, the average per capita fluid milk consumption is 0.9 cups per day. On average, Black/non-Hispanics consume approximately $1 / 2$ cup of milk per day, white/non-Hispanics consume 3/4 cup of milk per day, and Hispanics consume a little more than 3/4 cup of milk per day (Milk Industry Foundation, 1999). Data specifically on women indicates that American females consumed 1.3 servings of dairy foods per day (Miller, Groziak, \& DiRienzo, 1996). Mexican American women consumed an average of 1.64 servings of dairy products (Milk Industry Foundation, 1999). Although whole milk intake has declined by 180 percent in the past 25 years, whole and reduced fat $(2$ percent) milks continue to comprise at least $2 / 3$ of all milk consumed in the United States (Milk Industry Foundation, 1999).

Milk consumption and purchasing behaviors vary by age, gender, ethnicity and socioeconomic variables. Males tend to drink more milk than females in all age groups, with the most pronounced differences occurring between the ages of six and 24. A national consumer survey conducted between 1992 and 1993 discovered that among female homemakers, lower fat milks were purchased more frequently than higher fat milks by women who were older, of higher household income and education, and employed in professional, executive, administrative, or managerial positions. In addition, Caucasian women and women with smaller households and older children were greater consumers of low fat milk (Milk Industry Foundation, 1995).

The California Dietary Practices Survey, conducted every other year since 1989, uses telephone surveys of a representative sample consisting of 1,000 Californians (Foerster, $\mathrm{Wu}, \mathrm{Gregson}, \mathrm{Hudes}, \&$ Fierro, 1999). The representative sample increased to 1,700 in 1997. The adults surveyed reported the following consumption activity for a typical day:

- One third of African American respondents and one-quarter of other respondents consumed no milk, yogurt or cheese; 
- One-third of respondents ate two or more different milk products;

- Half of respondents drank milk (including chocolate milk and milkshakes);

- Milk consumption was highest among the youngest and oldest age groups and lowest among African Americans, with no difference by level of education or income in most survey years;

- Among milk drinkers, 25 percent drank whole milk, 40 percent drank reduced fat (2 percent fat), 12 percent drank lowfat (1 percent fat), and 23 percent drank nonfat milk;

- Ten percent of all responding adults ate yogurt;

- Yogurt consumption was lowest among African Americans respondents;

- One-fifth of those who reported eating cheese said they consumed reduced fat, lowfat, or fat free cheese.

\section{Barriers to Consuming Adequate Calcium}

\section{Barriers to Consuming a Healthful Diet}

In California, limited income African American, Caucasian, and Latino women identified four major barriers to healthy eating. 1.) Healthy foods such as lean meats, vegetables, and lower fat milks are often perceived as being less flavorful or tasty; 2.) healthy foods are perceived as more costly; 3.) familiar food products, such as whole milk, and food preparation methods, such as frying, are traditional and are chosen out of habit; and, 4.) commercials and advertisements for "junk" foods and fast foods are profuse (Chavez \& Juarez and Associates, 1997).

\section{Barriers to Milk Consumption}

A social marketing campaign promoting lowfat milk in a low-income, predominantly Latino inner-city community of Manhattan, New York, found that an important barrier to increasing consumption of lowfat milk was its limited availability. Lowfat milks were not stocked regularly at the small local Hispanic grocery stores, called bodegas, where most residents purchased their food. Storeowners did not stock lowfat milk because there was no demand. The campaign also noted that lowfat milks were not offered at preschool and after school centers and nonpublic schools within the community (Wechsler \& Wernick, 1992).

A study with pregnant women eligible for the Special Supplemental Nutrition Program for Women, Infants, and Children (WIC Program), which helps pregnant women, new 
mothers, and young children eat well and stay healthy, identified that the women bought beverages other than milk because milk spoils easily (Park \& Ureda, 1999).

\section{Lactose Intolerance}

Lactose intolerance refers to gastrointestinal symptoms that result from consuming more lactose, a type of carbohydrate found in milk, than the body can break down with the lactase enzyme. Approximately 25 percent of Americans are lactose intolerant and experience flatulence, bloating and/or diarrhea after consuming milk and milk products (McBean, 1998). The issue of lactose intolerance is an important one, as reported milkrelated gastric distress can be a strong predictor of milk consumption (Klesges et al., 1999). Lactose intolerant individuals often avoid dairy foods and may put themselves at risk for calcium deficiency (National Academy of Sciences, 1997).

Lactose intolerance is seen in as many as 90 percent of Asian Americans, 60 to 100 percent of Native Americans, 70 to 80 percent of African Americans, 53 percent of Mexican Americans and 15 percent of Caucasians (McBean, 1998). The literature on clinical lactose intolerance suggests that a higher proportion of women and older adults are affected by lactose intolerance (Klesges et al., 1999).

A study with pregnant women eligible for the WIC Program suggested that the perception that milk causes an upset stomach or other symptoms of lactose intolerance may be culturally based and transmitted by persuasive communication, rather than based on personal experience (Park \& Ureda, 1994). Current findings suggest that most persons with lactose intolerance can ingest eight ounces of milk, twice daily with the morning and evening meals, without experiencing symptoms. Consuming dairy products with meals or in smaller amounts may not cause symptoms. Regularly including milk and other dairy products that contain lactose in the diet may even enhance tolerance to lactose. In addition, some dairy products that contain less lactose, such as yogurt and cheese and lactose-reduced milks, may be well tolerated by lactose intolerant individuals (McBean \& Miller 1998).

\section{Competing Foods}

The changes over the past few decades in beverage consumption trends among Americans have major implications for bone health. The consumption of milk decreased from 30 gallons per person per year in 1973 to 24 gallons in 1996, while the consumption of soda dramatically increased from 27 gallons per person per year to 53 gallons within the same time period. The consumption of fruit juices increased slightly from six gallons per person per year to nine gallons, within the same timeframe. Bottled water increased significantly, from three gallons per person per year in the early 1980's to 12 gallons in 1996 (USDA, 1999). Soda contributes sugar, caffeine, and empty calories to the diet. The "Liquid Candy" article, published in the Nutrition Action newsletter of the Center for Science in the Public Interest, describes soda consumption as "a missed opportunity to drink lowfat milk, orange juice, or other beverage that could help cut the risk of osteoporosis, heart disease, stroke, and cancer" (Liebman, 1998). 


\section{Knowledge, Perceptions, and Attitudes about Calcium and Dairy Foods}

Misconceptions, as well as social and cultural attitudes, impact the acceptability of milk (McBean \& Miller, 1998). The misconception that lowfat milk is produced by adding water to whole milk was a common misconception identified by a social marketing campaign that promoted lowfat milk in a low-income, predominantly Latino inner-city community of Manhattan, New York. In some Latin American countries, milk may be watered down, so the thickness of whole milk may be a symbol of wealth for some immigrants (Wechsler \& Wernick, 1992). The misconception that milk and dairy products are fattening or high in cholesterol may be common among American women. Although whole milk is a major contributor of excess fat in the diets of Americans, lowfat dairy foods and calcium-fortified foods are widely available (Miller, Steinbach, \& Jarvis, 1995).

California focus groups conducted in 1997 and 1999 by the Network, with low-income African American, Caucasian and Latino women indicated that the women believed milk was a drink for children and that whole milk was nutritionally superior to reduced-fat versions (Foerster, Wu, Gregson, Hudes, \& Fierro, 1999).

A study of women ages 22 to 85 suggested that 97 percent of women associate calcium intake with osteoporosis, however, 25 percent of women do not know how to evaluate their calcium intake and are unaware that they are calcium deficient (Miller, Steinbach, \& Jarvis, 1995).

Discussion groups with the mothers of nine- to 12-year-old daughters revealed that mothers do not want to be told what they should do regarding their daughter's health, but they do appreciate practical information and tips on how they can help their daughters meet their calcium requirements. In addition, the mothers said they realized that they are important role models for their daughters and claimed they are willing to model behaviors that contribute to bone health. When asked about discussions relating to calcium and milk between mothers and daughters, two out of 17 of the mothers stated that they hadn't talked to their daughters about this in the past six months; nine stated that their daughters listen when they talk about the subject; and seven claimed it was very important to talk with their daughters about the subject (Fleishman-Hillard Inc., 1997).

\section{Sources and Channels of Nutrition Information}

Spanish-dominant Latinas in focus groups reported obtaining information regarding lowfat foods from doctors, nutritionists, school classes, clinics, magazines, television, radio, newspapers, pamphlets, and from the Head Start program. The WIC Program was also cited as a very reliable source of nutrition information. Doctors were the most trusted authority to impart nutrition information. Supermarkets were also cited by participants as a good place to find nutrition information. The opinions of the participants varied as 
to the reliability of information relayed by family members, friends and celebrities (Lopez \& Juarez and Associates, 1995).

California focus groups conducted in 1997 and 1999 with low-income African American, Caucasian, and Latino women, identified the following channels as appropriate for fruit and vegetable promotion: television, billboards, radio, the Internet, schools, grocery stores, farmer's markets, laundromats, clinics, pharmacies, recreation centers, women's shelters, worksites, and video stores (Chavez, 1999; Chavez \& Juarez and Associates, 1997).

In addition, a statewide survey of 657 pre- and post-menopausal California women ages 40-64 conducted by the California Center for Health Improvement and The Field Institute indicated that 44 to 63 percent of pre-menopausal women had not talked with their healthcare provider about nutrition, calcium supplementation, hormone replacement therapy, and exercise as ways to prevent osteoporosis (Kelch, 1998).

\section{Food Purchasing, Food Preparation, and Meal Patterns}

California focus groups conducted in 1997 and 1999 with low-income African American, Caucasian, and Latino women revealed that women generally report doing most of the shopping for and preparation of foods. However, children have a major influence on what is purchased and served. Milk is an item that is purchased during every shopping trip (Chavez \& Juarez and Associates, 1997).

These focus groups also revealed the following meal patterns and habits:

- Cold cereals were a commonly reported breakfast item, although some women mentioned that they did not eat breakfast.

- Working women reported that they had little time for breakfast and occasionally grabbed a coffee, milk, or juice.

- Most of the women reported eating lunch alone, either at home or at work.

- Participants generally prepared two meals per day during the week and reported that they usually ate dinner with their families.

- Frequently prepared meal items included spaghetti, ground and grilled beef, tacos, chicken, macaroni and cheese, and pizza.

\section{Physical Activity}

A 1993 study examining the roles of physical activity and calcium consumption in the primary prevention of osteoporosis concluded that consistent physical activity is one of the most effective bone health promotion strategies (Anderson \& Metz, 1993).

Exercises that stress the bone can stimulate bone formation. Studies have shown the 
positive effects of physical activity on bone development in childhood, adolescence, and young adulthood as well as bone maintenance in middle to late adulthood (Recker et al., 1992; Lohman et al., 1995; Welten et al., 1994). A study conducted in 1994 suggested that sedentary persons begin to lose bone in their 20s (Matkovic et al., 1994).

\section{Recommended Levels}

Lifestyle recommendations for building healthy bones include 30 minutes of weight bearing physical activity per day. Recent studies have suggested that physical activities such as walking or stair climbing, while excellent weight-bearing, aerobic-conditioning, and fitness-enhancing activities, may not benefit the bones as much as higher-impact activities, such as jumping rope, or resistive exercises, such as specific weight-lifting routines that strengthen the muscles. Resistive exercise may play a major role in enhancing bone mineralization and may need to be included in recommendations for bone health (Swezey, 1996).

\section{Actual Levels}

According to the Cardiovascular Disease Outreach, Resources and Epidemiology Profiles, the majority of Californians are sedentary or physically inactive, reporting no or irregular leisure-time physical activity the month the California's Behavioral Risk Factor Surveillance survey was conducted. The highest prevalence of physical inactivity was among Hispanic adults and adults 45 to 54 years of age (Tables 4 and 5).

\begin{tabular}{|l|c|}
\hline \multicolumn{2}{|c|}{$\begin{array}{c}\text { Table 4: Prevalence of Physical Inactivity } \\
\text { Among California Female Adults, 1984-1996 }\end{array}$} \\
\hline White & $50.6 \%$ \\
\hline Black & $53.9 \%$ \\
\hline Hispanic & $66.2 \%$ \\
\hline Other & $63.2 \%$ \\
\hline $\begin{array}{l}\text { Reference: Cardiovascular Disease Outreach, Resources and Epidemiology Profiles, } \\
\text { Report No. 5 }\end{array}$ \\
\hline
\end{tabular}

Prepared by Department of Health Services 


\begin{tabular}{|l|c|}
\hline \multicolumn{2}{|c|}{$\begin{array}{c}\text { Table 5: Prevalence of Physical Inactivity } \\
\text { Among California Adults By Age Group, 1996 }\end{array}$} \\
\hline $18-24$ & $55.5 \%$ \\
\hline $25-34$ & $53.8 \%$ \\
\hline $35-44$ & $56.6 \%$ \\
\hline $45-54$ & $52.6 \%$ \\
\hline $55-64$ & $54.9 \%$ \\
\hline $65+$ & $54.4 \%$ \\
\hline $\begin{array}{l}\text { Reference: Cardiovascular Disease Outreach, Resources and Epidemiology Profiles, } \\
\text { Report No. 5 }\end{array}$ \\
\hline
\end{tabular}

Prepared by Department of Health Services

\section{Physical Activity Preferences}

Low-income African American, Caucasian, and Latino women taking part in recent focus groups in California reported walking as their most common physical activity. Many women reported walking with their children, at work, or around the block to get exercise. Among limited income mothers, opportunities for physical activity also included bicycling, chasing the kids around the house, dancing with their children, and doing garden or yard work. Exercising alone or with other adults was an uncommon practice among African American, Caucasian, and Hispanic mothers (Chavez \& Juarez and Associates, 1997).

A study of urban American women found that walking was by far the most frequently reported leisure time physical activity. Weightlifting was the second most frequently reported leisure time activity among white and Mexican American women, while stationary cycling was the second most popular activity for African American women (Ransdell \& Wells, 1998). Among women in the contemplation and preparation stages of change, physical activities associated with daily living, such as house and yard work, become the more preferred form of physical activity. This preference increased with age (Scharff, Homan, Kreuter, \& Brennan, 1999).

Some important predictors of physical activity behaviors are age and marital status. Younger women reported performing more physical activity than older women (Scharff, Homan, Kreuter, \& Brennan, 1999). Marital status can be a significant predictor of leisure time physical activity. African American and Mexican American women who were married were more likely to be highly active than those who were single, divorced, or widowed, reported one study (Ransdell \& Wells, 1998).

\section{Barriers to Physical Activity}

Interviews with a nationally representative sample of approximately 1,000 adults revealed that among those who believe they are not getting enough exercise, 33 percent said it was because of their job, 27 percent cited lack of interest or motivation, 
19 percent cited lack of time, and 13 percent cited health problems (National Association for Sport and Physical Education, 2000).

A study investigating factors associated with levels of physical activity among adult women ages 18 to 75 revealed that the youngest women reported the most barriers to physical activity, while the oldest women reported the fewest barriers (Scharff, Homan, Kreuter, \& Brennan, 1999).

Among low-income African American, Caucasian, and Latino women in California, lack of motivation, time, proper equipment/shoes, support and reinforcement, such as exercise classes for larger women, were barriers to physical activity (Chavez \& Juarez and Associates, 1997). Another identified barrier to regular exercise was the perception that the regular daily routine provides enough physical activity (Chavez \& Juarez and Associates, 1997). A physical activity and nutrition education program implemented within an African American community in Stockton, California, also identified this misconception. Participants believed that employment status determined one's level of physical activity. Being employed was seen as being physically active, while laziness was synonymous with physical inactivity or a sedentary lifestyle among the participants (Williams \& Olano, 1999).

\section{Knowledge, Perceptions, and Motivators to Physical Activity}

Low-income African American, Caucasian, and Latino women in California believed exercise relieves stress, increases vitality and health, and promotes sleep and weight loss. The women also believed that the benefits for children include releasing energy and assisting in socio-emotional development (e.g. independence, social skills, etc.) (Chavez \& Juarez and Associates, 1997). However, mothers were less familiar with the role exercise plays in promoting bone health than the role of calcium and milk (Fleischman-Hillard Inc., 1997).

A study of women 18 to 75 years of age in Missouri found that older women cite health as the primary reason for wanting to be physically active, while younger women report weight maintenance as their primary motivator (Scharff, Homan, Kreuter, \& Brennan, 1999).

The benefits of feeling energized and of being an example for one's children have been identified as motivators in focus groups with low-income, African American, Caucasian, and Latino women in California. Women may be more apt to be physically active if they were provided incentives, such as childcare or a free day at the gym, a friend to exercise with, and community involvement in some way (Chavez \& Juarez and Associates, 1997).

A physical activity and nutrition education program implemented within an African American community in Stockton, California, identified community betterment as an important motivator. Community walking clubs were integrated into neighborhood crime prevention strategies. The participants were more readily mobilized and motivated 
when they believed the walking activity benefited their community. Among members of the community, little appreciation or awareness of physical activity existed; therefore, a goal beyond health promotion became an important motivator (Williams \& Olano, 1999).

\section{Sources and Channels for Physical Activity Information}

Low-income African American, Caucasian, and Latino women in California reported in focus groups that they would like to receive information on the benefits of physical activity near the produce aisle in grocery stores, in doctors' offices, and through traditional media and broadcast vehicles such as mail, ads, brochures, and bulletin boards. The women reported that they would like to receive more specific tips and information on exercises and physical activities from brochures, television, the Internet, and in schools and doctors' offices. More particularly, African American women reported that television ads with physical activity messages should be shown during cartoon and soap opera timeslots and on the beginning of video rentals. African American women were the only women to mention worksites as a possible location to receive information regarding physical activity (Chavez, 1999; Chavez \& Juarez and Associates, 1997).

\section{Overview of Dairy and Physical Activity Campaigns}

\section{Adelante Con Leche Semi-Descremada de Uno Por Ciento (Mooo-ve Ahead with One Percent Milk)}

In association with the Center for Science in the Public Interest, in conjunction with the Santa Paula Health Action Coalition, and with funding through The California

Endowment's Children's Health Initiative, the California Adolescent Nutrition and Fitness Program (CANFit) implemented the Adelante Con Leche Semi-Descremada de uno por ciento (Mooo-ve Ahead with one per cent Milk) campaign in the low-income, predominantly Latino community of Santa Paula in the fall of 1998 . The campaign targeted Santa Paula's milk-drinking Latino youth and their parents in order to increase the consumption of lower fat milk as a way to lower dietary fat, saturated fat, and calories. The intensive six-week campaign included the following advertising and educational components: 1.) shelf talkers in the dairy section of participating stores (two major supermarkets and nine small neighborhood markets); 2.) Spanish language radio ads; 3.) signs on the windows of participating stores; 4.) paid advertising in English and Spanish language newspapers; 5.) promotional incentive items; 6.) milk taste tests in supermarkets and community events; and 7.) nutrition presentations at schools, civic organizations, and churches. The effectiveness of the campaign was measured by conducting a survey of milk sales at participating grocery stores. At the end of the six-week media and public relations campaign, sales of 1 percent and fat-free milk had increased by 60 percent in Santa Paula. All milk sales rose from 54,530 gallons to 89,038 gallons after the six-week campaign. Sales of low fat (1 percent fat) milk rose from 3,181 gallons to 11,530 gallons. Six-month post-campaign milk sales data is forthcoming. Campaign planners attributed the success of this campaign to personal contact with grocery store owners, radio advertising, radio talk shows, and the support of key community leaders such as a minister and a school superintendent. 


\section{A Social Marketing Campaign to Promote Low-fat Milk Consumption in an Inner- city Latino Community}

The Washington Heights-Inwood Healthy Heart Program, a community-based cardiovascular disease prevention agency, implemented a social marketing, low fat milk campaign in a low-income, inner-city, Latino community near New York City. The campaign objective was to urge consumers to switch from whole milk to low fat milk. The campaign built support from key community leaders and organizations, local school districts, parent associations, churches, radio stations, and a coalition of child care agencies. The campaign was effective in increasing the consumer demand for low fat milk by utilizing a mix of traditional health education methods delivered in English and Spanish; intensive local media publicity through press releases and public service announcements; and marketing techniques such as milk taste tests, a milk label collection contest, and the distribution of coupons for low-fat milk at churches and schools. Institutional changes, such as the availability of low fat milk in schools and other institutions, was promoted as a way to sustain the behavior change.

\section{La Vida Caminando: A Community-Based Physical Activity Program Designed by and for Latino Families}

In partnership with four small rural cities in the San Joaquin Valley of California, the Fresno County Human Services System's Diabetes Education Project launched La Vida Caminando in 1994 with funding from the DHS ON THE MOVE! Physical Activity and Health Initiative. Walking clubs were organized as a way to attract Latino families with children of all ages. Much of the promotion of the clubs occurred through word of mouth. The walking clubs were held in the evening at community or senior centers or school facilities. Clubs were free of charge; provided educational materials and tools in English and Spanish languages on topics such as heart rate, goal setting, and the use of a logbook to chart progress; and included shared meals or snacks. Though the project was successful in recruiting and involving the participants, a downward trend in physical activity was observed. This may have been due to inaccurate self-reported time spent walking for physical activity.

\section{Mobilizing and Maintaining a Coalition to Promote Physical Activity Among African Americans in Southeast Stockton, California}

A collaborative partnership between the San Joaquin County Public Health Services, an African American health coalition, and a neighborhood-based community services agency integrated walking clubs into many aspects of communities in Stockton, California. The staff and coalition established walking as the community norm by incorporating walking clubs into community activities, such as crime prevention efforts and youth projects. Though the project originally promoted walking as a way to improve hypertension, the integration of walking into crime prevention efforts was extremely successful in reducing barriers to walking regularly and in promoting community unity. Conducting a needs assessment contributed to the success of the project as it allowed 
the coalition members to decide where to concentrate efforts and resources to make the most impact. Ongoing marketing at community celebrations and events also contributed to the success. 


\section{REFERENCES}

Alaimo, K., McDowell, M., Briefel, R., Bischof, A., Caughman, C., Loria, C., \& Johnson, C. (1994). Dietary intake of vitamins, minerals, and fiber of persons ages 2 months and over in the United States: Third National Health and Nutrition Examination Survey, Phase 1, 1988-91. (Advance Data, No. 258). U.S. Department of Health and Human Services, Centers for Disease Control and Prevention, National Center for Health Statistics.

American Academy of Pediatrics. Calcium requirements of infants, children, and adolescents. Available at: http://www.aap.org/policy/re9904.html. Accessed April 2000.

Anderson, J., \& Metz, J. (1993). Contributions of dietary calcium and physical activity to primary prevention of osteoporosis in females. Journal of the American College of Nutrition, 12(4), 378-383.

Bertron, P., Barnard, N. D., \& Mills, M. (1999). Racial bias in federal nutrition policy, Part I: The public health implications of variations in lactase persistence. Journal of the National Medical Association, 91(3), 151-7.

Block, G., Norris, J. C., Mandel, R. M., \& DiSogra, C. (1995). Sources of energy and six nutrients in diets of low-income Hispanic-American women and their children: quantitative data from Hispanic Health and Nutrition Examination Survey, 1982-1984. Journal of the American Dietetic Association, 95(2), 195-208.

Chavez, R., \& Juarez and Associates. (1997, November). Focus group research with low income White, African American, and Latino women with school-aged children who do and do not use food stamps. Cancer Prevention and Nutrition Section, California Department of Health Services.

Chavez, R. (1999, December). California Nutrition Network concept development and testing for fruit and vegetable consumption \& physical activity. Cancer Prevention and Nutrition Section, California Department of Health Services.

Dairy Council of California. Hot topics in health and nutrition- A primer. Available at: http://www.dairycouncilofca.org/hp/hp hot prim.htm. Accessed April 2000.

Fleishman-Hillard Inc. (1997, December). A focus group report to: National Osteoporosis Foundation.

Fleming, K., \& Heimbach, J. (1994). Consumption of calcium in the U.S.: Food sources and intake levels. Journal of Nutrition, 124 (Supplement), 1426S-1430S.

Foerster, S.B., Wu, S., Gregson, J., Hudes, M., \& Fierro, M.P. (1999). California Dietary Practices Survey: Overall trends in healthy eating among adults, 1989-1997, A 
call to action, Part 2. Sacramento, California: California Department of Health Services.

Ford, E. (1998). Race, education, and dietary cations: Findings from the Third National Health and Nutrition Examination Survey. Ethnicity and Disease, 8(1), 10-20.

Gazzaniga, J. M., Kao, C., Cowling, D. W., Fox, P., Davis, B., \& Wright, W. E. (1998). Cardiovascular disease risk factors among California adults, 1984-1996.

Cardiovascular Disease Outreach, Resources and Epidemiology (CORE) Program, University of California San Francisco and California Department of Health Services.

Gerrior, S., \& Bernie, L. (1997). Nutrient Content of the US Food Supply, 1909-94. (Home Economics Research Report No 53.) Washington, D.C.: US Department of Agriculture.

Grassi, K., Gonzalez, M., Tello, P., \& He, G. (1999). La Vida Caminando: A community-based physical activity program designed by and for rural Latino families. Journal of Health Education, 30(2), S13-S17.

Guendelman, S., \& Adams, B. (1995). Dietary intake among Mexican-American women: Generational differences and a comparison with White Non-Hispanic women. American Journal of Public Health, 85(1), 20-25.

Heaney, R. P. (1996). Bone Mass, Nutrition, and Other Lifestyle Factors. Nutrition Reviews, 54(4), S3-S10.

International Dairy Foods Association, Milk Industry Foundation. (1999). Milk Facts. Washington D.C.: Author.

Kelch, D. (1998). Changing the healthcare landscape: Baby boomers focus on education, prevention as they approach menopause. The Field Institute, California Center for Health Improvement, and the Foundation for Osteoporosis Research and Education.

Klesges, R. C., Harmon-Clayton, K., Ward, K. D., Kaufman, E. M., Haddock, C. K., Talcott, G. W., \& Lando, H. A. (1999). Predictors of milk consumption in a population of 17- to 35-year-old military personnel. Journal of the American Dietetic Association, 99(7), 821-826.

Liebman, B. (1998). Sugar- the sweetening of the American diet. Nutrition Action Healthletter, 25(9), 3-8.

Leslie, M., \& Pierre, R. (1999). Osteoporosis: Implications for Risk Reduction in the College Setting. Journal of American College Health, 48, 67-71. 
Lohman T., Going, S., Pamenter, R., Hall, M., Boyden, T., Houtkooper, L., Ritenbaugh, C., Bare, L., Hill, A., \& Aickin, M. (1995). Effects of resistance training on regional and total bone mineral density in premenopausal women: A randomized prospective study. Journal of Bone and Mineral Research, 10(7), 1015-1024.

Looker, A.C., Johnston, Jr., C.C., Wahner, H.W., Dunn, W.L., Calvo, M.S., Harris, T.B., Heyse, S.P., Lindsay, R.L. (1995). Prevalence of Low Femoral Bone Density in Older U.S. Women From N.H.A.N.E.S. III. Journal of Bone and Mineral Research, 10(5), 799.

Lopez A., \& Juarez and Associates, Inc. (1995). Eating Habits of Latinos. California Department of Health Services, California Project LEAN.

Matkovic, V., Jelic, T., Wardlaw, G. M., Ilich, J. Z., Goal, P. K., Wright, J. K., Andon, M. B., Smith, K. T., \& Heaney, R. (1994). Timing of peak bone mass in Caucasian females and its implications for the prevention of osteoporosis. Journal of Clinical Investigation, 93, 799-808.

McBean, L. D., \& Miller, G. D. (1998). Allaying fears and fallacies about lactose intolerance. Journal of the American Dietetic Association, 98(6), 671-6.

“Milk Facts," 1999 Edition, Milk Industry Foundation, Washington D.C., August 1999.

Miller, G., Groziak, S., \& DiRienzo, D. (1996). Age considerations in nutrient needs for bone health. Journal of the American College of Nutrition, 15(6), 553-55.

Miller, G., Steinbach, T., \& Jarvis, J. (1995). The challenge: Motivating women to increase calcium intake from dairy foods. Journal of the American College of Nutrition, 14(4), 309-10.

National Academy of Sciences, Standing Committee on the Scientific Evaluation of Dietary Reference Intakes, Food and Nutrition Board, Institute of Medicine. (1997). Dietary Reference Intakes For Calcium, Phosphorus, Magnesium, Vitamin D, and Fluoride. Washington DC: National Academy Press, 71-145.

National Institutes of Health, Consensus Conference on Optimal Calcium Intake. Consensus Statement: Optimal Calcium Intake [On-line]. Available at: http://text.nlm.nih.gov/nih/cdc/www/97txt.html.

National Institutes of Health, Consensus Panel Addresses Osteoporosis Prevention, Diagnosis, and Therapy (On-line). Available at: http://www.nih.gov/news/pr/mar2000/od-29.html. Accessed March 2000.

National Institutes of Health, Osteoporosis and Related Bone Disorders, National Resource Center. Latino Women and Osteoporosis [On-line]. Available at: http://www.osteo.org/latino.html. Accessed April 2000. 
National Institutes of Health, Osteoporosis and Related Bone Disorders, National Resource Center. Osteoporosis and African-American Women [On-line]. Available at: http://www.osteo.org/afrc amer.html. Accessed April 2000.

National Osteoporosis Foundation. (1997, January). 1996 and 2015 Osteoporosis prevalence figures: State-by-state report. Washington, DC: Author.

National Association for Sport and Physical Education. (2000). Public Attitudes Toward Physical Education: Are Schools Providing What the Public Wants?, survey conducted by the Opinion Research Corporation International.

Park, K. \& Ureda, J. (1999). Specific Motivations of Milk Consumption among Pregnant Women Enrolled in or Eligible for WIC. Journal of Nutrition Education, 31(2), 76-85.

Ransdell, L. B., \& Wells, C. L. (1998). Physical activity in urban white, AfricanAmerican, and Mexican-American women. Medicine and Science in Sports and Exercise, (11), 1608-1615.

Recker, R., Davies, M., Hinders, S., Heaney, R., Stegman, M., \& Kimmel, D. (1992). Bone gain in young adult women. Journal of the American Medical Association, 268(17), 2403-2408.

Rodin, A., Murby, B., Smith, M., Caleffi, M., Fentiman, I., Chapman, M. G., \& Fogelman, I. (1990). Premenopausal bone loss in the lumbar spine and neck of femur: A study of 225 Caucasian women. Bone, 11, 1-5.

Scharff, D. P., Homan, S., Kreuter, M., \& Brennan, L. (1999). Factors associated with physical activity in women across the life span: implications for program development. Women and Health, 29(2), 115-134.

Swezey, R. (1996). Exercise for osteoporosis-ls walking enough? Spine, 21(23), 2809-2813.

USDA, Food and Rural Economics Division, Economic Research Service. (1999). America's eating habits: Changes and consequences. (Agriculture Information Bulletin No. 750 ).

U.S. Public Health Service's Office on Women's Health, U.S. Department of Health and Human Services, and the National Osteoporosis Foundation. (1996, September). Summary Proceedings of the National Osteoporosis Education Campaign Task Force Meeting, Washington, D.C.

Young, D. R., Miller, K. W., Wilder, L. B., Yanek, L. R., \& Becker, D. M. (1998). Physical activity patterns of urban African Americans. Journal of Community Health, 23(2), 99-112. 
Weaver, C. (1997). "Calcium: Myth vs. Reality," course hand-out, Purdue University, West Lafayette, IN, 1997.

Weaver, C. (1994). Age Related Calcium Requirements Due to Changes in Absorption and Utilization. Journal of Nutrition, 124(14), 18S-25S

Wechsler, H. \& Wernick, S. (1992). A social marketing campaign to promote low-fat milk consumption in an inner-city Latino community. Public Health Reports, 107(2), 202-207.

Welten, D.C., Kemper, H. C. G., Post, G. B., Van Mechelen, W., Twisk, J., Lips, P., \& Teule, G. J. (1994). Weight-bearing activity during youth is a more important factor for peak bone mass than calcium intake. Journal of Bone and Mineral Research, 9(7), 1089-1096.

Williams, L. \& Olano, V. Mobilizing and maintaining a coalition to promote physical activity among African Americans in southeast Stockton, California. Journal of Health Education, 30(2), S31- 36.

Women's Health Council, Association of State and Territorial Chronic Disease Program Directors. (1999, November). Osteoporosis 2000: A resource guide for state programs.

Washington, D.C.: Author. 